\title{
Derivaciones subjetivas en la contemporaneidad (A propósito Pandemonia Panacea)
}

\author{
Subjective derivations in contemporary (By the way Pademonia
}

Panacea)

Edilberto HERNÁNDEZ. Universidad de San Buenaventura (Colombia). edilberto.hernandez@usbmed.edu.co

Resumen: El proyecto artístico: Pandemonia Panacea me permitió realizar ciertos acercamientos experimentales, sensibles y vitales, encaminados a comprender algunos aspectos de la constitución de las subjetividades en la contemporaneidad y derivar de ello, inquietudes referidas a la formación y la manera de establecer relaciones más cuidadosas con todos los seres que habitamos el universo. Estas indagaciones se han construido desde una perspectiva de cognición estética, esto es, un modo de construcción y de relación con la realidad, en la que se reconocen las posibilidades de comprensión y actuación sensible. A partir de un encuadre inicial, el artículo profundiza la cuestión de las subjetividades contemporáneas, para entrar luego a desarrollar dos formas de derivaciones subjetivas.

Palabras clave: Subjetividades contemporáneas, Subjetividades celebrity, Cuerpo, Cognición estética, Pandemonia Panacea.

Abstract: The artistic project: Pademonia Panacea allowed me to make certain experimental, sensitive and vital approaches, aimed at understanding some aspects about constitution of Subjectivities through contemporaneity, and because of it, being concerned to formation and way to establish more careful relations with all beings that inhabit the universe. These inquiries have been built from a perspective of aesthetic cognition, it means, a pathway of construction and relation with reality, in which the possibilities of understanding and sensitive action are recognized. From an initial framing, the article goes further into the question related to contemporary subjectivities, in order to develop two ways of subjective derivations. 
Keywords: Contemporary Subjectivities, Subjectivities celebrity, Body, Aesthetic cognition, Pademonia Panacea.

\section{Introducción}

La experiencia humana de aprender, de aprehendernos, de entrar en relación con el mundo que nos rodea, conforma un conjunto de prácticas institucionales, gestuales y sensibles a través de las cuales devenimos subjetividades. Gran parte de estas prácticas están claramente intencionadas a conducirnos hacia diferentes órdenes sociales. Sin embargo, pese a la eficiencia de los regímenes, la subjetividad de forma intuitiva va encontrando grietas para configurarse a su manera; encontrar las grietas, penetrar en ellas y expandirlas no es una labor sencilla, esto demanda decisiones audaces para asumir el ropaje necesario para actualizar formas de presencia inesperadas.

Ahora bien, hasta hace un tiempo se pensaba que los regímenes sociales, a través de instituciones como la familia, la escuela, el colegio y la universidad, eran -en ese orden- las principales responsables de los procesos de subjetivación y por tanto, su papel en la configuración de subjetividades era crucial. Actualmente pareciera ser un poco más claro, que la constitución de la subjetividad no transita por las estructuras tradicionalmente establecidas, lo que no indica que la institucionalidad, pese al carácter gaseoso que ha adquirido en los últimos años, haya dejado de incidir en tales configuraciones.

Los procesos de configuración de subjetividades representan experiencias performáticas, en el sentido de un acontecer inmerso en el universo de la información, tal como lo visualiza David Bohm (1988) en La totalidad y el orden implicado; o bien una derivación de la experiencia de estar sumergidos en el lenguaje en el sentido que lo propone Gilles Deleuze en Empirismo y subjetividad. (2007) Las formas subjetivas que se constituyen a través de la inmersión en la información o en el lenguaje, según la perspectiva que se prefiera, no son una acción que pueda ser situada específicamente, se construyen en la experimentación, como universo sensible en el cual transcurre la existencia humana y que hace lazos subjetivos de maneras inusitadas, tal como lo hacen esos fantasmas que rozan la piel y al instante desaparecen.

La información deviene subjetividades en cuanto ella constituye un régimen sensible, tal como lo entiende Jacques Rancière (2005) en su texto, Sobre políticas estéticas. Las posibilidades de configuración de subjetividades son un tanto inciertas, por un lado, responden al desenvolvimiento de la información y por el otro, a la manera como correspondemos a tales desenvolvimientos; se trata de recorrer un bosque de niebla, en el cual se hace necesario intuir permanentemente la manera de conducirnos a nosotros mismos, intuir la manera de contener el deseo de conducir a los otros y resistir las fuerzas que buscan conducirnos a sus fines. Las travesías por 
bosques nublados precisan de una gran clarividencia para reconocer los idealismos y la seducción almibarada del consumismo banal; también gran lucidez para desconfiar de esos realismos que esterilizan las fertilidades geográficas y sensibles.

Esta es la vía de la cognición estética, perspectiva de construcción de conocimiento y de construcción de sí, en la que se reconocen las posibilidades de comprensión y actuación desde el cuidado con las formas de construir la realidad e intervenir en ella. Para la cognición estética la palabra no es solo un medio de interacción con el mundo. El lenguaje, la palabra, y el pensamiento son formas de acariciar, de desplegar un cuerpo que va a los otros; un cuerpo hondamente sensible que se detiene en las series de tonalidades de las ideas, en las gamas de colores de los conceptos, de los otros cuerpos y de las subjetividades.

La cognición estética es una manera intuir la diferencia, de ir tras lo singular. El mar, a lo lejos se presenta plano y azulado, pero al acercamos y levantar las capas superficiales, gratamente aparecen las gotas de mar con nombres propios. Autopistas de ballenas viajeras, fiestas de tortugas longevas, medusas misteriosas salpicando las aguas. Intuir la diferencia es una acción creadora, pues la captura de las sutiles diferencias es quizás, uno de los principales gestos de la creación y de comprensión del arte. La intuición creadora se acompaña de asombros permanentes para percibir los movimientos de la vida y los miedos que conducen a la inmovilidad. El miedo constituye un reverso árido de las cosas, fotografías que petrifican la humedad y la ternura del rocío que despierta nuestras montañas andinas al amanecer. Más allá de toda turbación, la potencia creadora de la subjetividad logra ocupar lugares insólitos, inventan órganos y gestos para expandir el espacio y empujar la opacidad de ciertas quietudes que resisten.

La intensidad de la subjetividad convoca la invención de un cuerpo para cada trayecto de existencia. Series de cuerpos tocan a la puerta de nuestra casa, y traen noticias de los cambios de piel, aunque no siempre consentimos su ingreso. Las invenciones subjetivas y los modos de ponerlas en relación con los otros, significa también, inventar un cuerpo que habite tales invenciones. Hay veces que los cuerpos inventados se arrastran por la espesura de los laberintos que forjamos para evitar nuestra expansión. Otras veces la suavidad de los cuerpos de felinos y de reptiles nos muestran los agujeros para salir y crear otros mundos en los que habitar más holgadamente.

Ahora bien, las prácticas artísticas conforman un régimen sensible en particular, son prácticas que participan al igual que otros aspectos de la cotidianidad en la configuración de subjetividades, unas veces como acciones pedagógicas, otras solo, como resonancias dado que hay experiencias artísticas que responden exclusivamente a sus propias reglas, reinventan la manera de entender la vida y dejan entrever que ciertos estados de equilibrio equivalen a una petrificación de la existencia. 
Distinguir los matices que separan una práctica artística (o cultural en general) de otra no tiene mayor importancia en este momento, pues la configuración subjetiva es una experiencia performática, como ya he insinuado, y no dependen necesariamente de las intencionalidades; los procesos de subjetivación son guiados, de cierto modo, por la incertidumbre. Esta perspectiva, me permite ubicar el proyecto artístico Pandemonia Panacea, en la vía de lo incierto, ya que el arte, como práctica humana moviliza las emociones, conecta mundos aparentemente distintos y distantes: interior-exterior, materia-espíritu, razón-sensibilidad, en este sentido, las prácticas artísticas, constituyen experiencias que comunican, liberan las capacidades de expansión subjetiva y configuran sensibilidades propias.

La incertidumbre igualmente, prepara para la frustración, la irrupción de lo nuevo, trae consigo un rastro profundo de soledad y muerte, pues a veces el cuerpo anterior no encaja y entonces, falta la música, el abismo de la pregunta resulta insoportable, solo un poco de deseo ronda por ahí para decirnos que también nosotros mismos estamos ausentes; en momentos así, lo fúnebre se recrea meticulosamente, asistimos a pequeñas muertes, muertes transitorias; capas y capas de silencio sobrevienen, silencio que penetra la piel y descompone los cuerpo. Silencio de lo orgánico. Silencio de la tierra. A lo lejos se escucha un leve palpitar, un leve palpitar de los tonos del silencio, fragilidad del silencio, miedo al silencio. Una oscuridad cálida sobreviene e invita a producir en ella otros matices de la subjetividad.

Siguiendo de alguna manera el camino de la intuición creadora, éste trabajo, acerca de la posibilidad de entender el proyecto artístico Pandemonia Panacea, en el contexto de la configuración de subjetividades contemporáneas, se propone generar reflexiones que aporten a la comprensión de la intensidad con la que estamos juntos, como comunidades humanas y como seres inmersos en un universo vivo y donde cada ser, grade o minúsculo es parte fundamental del tejido de la vida.

Las reflexiones que propongo muestran algunas vertientes por donde transcurren las experiencias de subjetivación en la contemporaneidad y hacer notar cómo éstas experiencias son la posibilidad de ensanchar nuestras sensibilidades para acercarnos respetuosamente a los otros, poder vibrar y contribuir al oleaje de las fuerzas vitales que recorren amorosamente el universo. Este trabajo también, apunta a reconocer esas formas originales como el arte contemporáneo busca generar inquietud, vislumbrar maneras de relacionarnos con los otros y alentar en medio de bullicio contemporáneo, que nuestro destino humano sigue estando atado a las aves que surcan las praderas, a los peces que juguetean en las aguas, a los animales que transitan sus propios caminos, a los árboles que se han detenido para contemplar los atardeceres.

Subjetividades contemporánea

La contemporaneidad se presenta caótica, volátil y desafiante; en cierto modo, todo presente lo es. Las dificultades de percepción del presente no radican en él en sí 
mismo; somos nosotros, es nuestro propio acontecer, nuestro propio cuerpo que se ve ofuscado con tantos olores, formas y rostros. El tiempo transcurrido posee una intensidad decreciente y viene a nosotros liviano y selectivo, sus aristas escabrosas suelen quedarse en el camino.

Sin embargo, es en el presente como experiencia existencial donde las subjetividades escenifican sus dramas; en el presente, el universo subjetivo se hace cuerpo y se torna consciente de su propio acontecer. Suely Rolnik (2002), pensadora brasileña, esboza sus ideas en torno al proceso de construcción de la subjetividad en estos términos:

La subjetividad es el laboratorio vivo donde universos se crean y otros se disuelven. Son muchas las políticas de subjetivización y los modos de relación con la alteridad del mundo que tales políticas implican, combinaciones variadas y variables de dos modos de aprehensión y de relación con el mundo en cuanto materia: como dibujo de una forma o como campo de fuerzas; modos estos que, a su vez, dependen de la activación de diferentes potencias de la subjetividad. (p. 1)

Las subjetividades se constituyen a partir de complejos movimientos y conversaciones, se trata de un tejido multidimensional de formas singulares, en un tiempo presente, que es el escenario donde se construye, se produce y se reproduce de manera constante, ese acontecimiento a que refiere una existencia, una subjetividad. Entonces, la experiencia de configurar sentidos distintos y construir visiones del mundo, por fuera de los sistemas de prácticas coactivas impuestas históricamente en nuestras sociedades es toda una aventura para la subjetividad. Pues se trata de un acontecer, donde lo dado socialmente y el deseo propio conversan de forma ininterrumpida. Es por ello que las prácticas de subjetivación no pueden ser unificadas en estructuras de comprensión unidimensionales, como lo supuso, por ejemplo, el marxismo, paradigma que presuponía una estructura subjetiva un tanto bipolar: explotadores - explotados.

Los regímenes sociales totalitarios, y también los que no se reconocen como tal, poseen sus propios sistemas estratégicos de subjetivación, pero es igualmente cierto, que la configuración de subjetividades implica, una experiencia de desenvolvimiento personal y esta genera agitaciones en sentidos muy diversos. Agitaciones que a veces tienden a la identificación, a veces a la resistencia y, otras veces a la indiferencia y la marginalidad. Aguas, montañas, desiertos, paisajes lunares, cualquiera sea el lienzo, las fuerzas creativas de algunas subjetividades revelan en éste su coraje.

Por su parte, Roland Barthes (2009) en su texto El Susurro del Lenguaje, describe las subjetividades como un movimiento del lenguaje. Al referirse al lector dirá que éste: "resulta atrapado en una inversión dialéctica: finalmente, ya no decodifica, sino que sobre-codifica; ya no descifra, sino que produce, amontona lenguajes, se deja atravesar por ellos infinita e incansablemente: él es esa travesía" (p.57). El lenguaje, es por tanto el componente sensible a través del cual, realizamos la 
experiencia subjetiva. La subjetividad, entonces, hace referencia a nuestra forma existencial de participar activamente del mundo que nos rodea, de construirlo como lenguaje y como escenario donde se desarrolla la vida personal, comunitaria y cósmica. Acontecemos subjetividades en forma de ruidos visuales, ronquidos metálicos sobre el asfalto, acontecer digital, subjetividades puramente cibernéticas; experiencias y gestos del transcurrir de la existencia.

Hay movimientos subjetivos que aguardan pacientemente el tiempo propicio para realizar la singularidad de sus pronunciamientos ya que, una subjetividad requiere de un cuerpo en el cual configurar y se reconfigurar la experiencia humana en el tiempo y en el espacio. Cuerpo que es superficies, arcilla cálida, mármol resistente, madera quebradiza; materia orgánica que adquiere forma a través de la experimentación constante que representa el existir cotidiano.

La subjetividad es una experiencia particularmente corporal, su forma, refiere a un tejido áspero y de múltiples dimensiones, construido los hilos de la experimentación. Las formas corporales de la experiencia subjetiva se configuran en una duración incesante, como un bailarín en el escenario que empapa de movimiento una serie de coordenadas cartografiadas previamente y demarcadas durante la escena por ondas de luz; el bailarín se eleva sobre la superficie del escenario y por un instante estará suspendido en el espacio, el cuerpo ocupa entonces, el centro del escenario, mientras todo lo demás permanece constante, apenas latiendo.

Los gestos corporales, comprenden formas deliberadas, en el sentido que la impresión de la experiencia existencial que da consistencia a un cuerpo, está guiada precisamente, por nuestra manera de experimentar y reconfigurar la propia trayectoria existencial. Nuestros cuerpos están hechos de jirones de deseo, de pequeños trozos de experiencia tomadas al paso, de tramos de silencio y desasosiegos marginales. Nuestros cuerpos están escritos a través de ritmos aleatorios como composiciones de Stockhausen o Pierre Boulez. Los cuerpos subjetivos no se corresponden con series de secuencias narrativas construidas a partir de fragmentos perceptivos, un cuerpo concebido como narración presenta demasiadas restricciones para decir los movimientos del miedo, del asombro y de la intrepidez de la creación. Los cuerpos como acontecimientos subjetivos no solo, suelen llevar consigo dolores más antiguos, sino que a veces se convierten en un río turbulento del cual solo vemos las ondas que compone el fluir de sus aguas, pero ignoramos lo que se arrastra por sus profundidades.

Los cuerpos acontecen en forma de gestos, de movimientos experimentales, de los gritos y los susurros que provoca la fricción con otros cuerpos, de las sombras de la zozobra, del miedo y el terror que no cesa. Un cuerpo que acontece, a diferencia de un cuerpo narrado, interroga las gestualidades que pretendemos adquirir cuando algo nos pasa, pues la presencia en el acontecer, nos mueve a hacer algo distinto, más allá de la repetición o la reproducción del gesto recordado. 
Muchas de las capas de cuerpo subjetivo, están representadas por preguntas sobre la existencia, preguntas por las estructuras orgánicas que las constituyen, por lo que ellas, como cuerpos sin órganos ${ }^{1}$ son capaces de producir y lo que nosotros somos capaces de producir en ellas y a través de ellas, una veces para alentar la creación y otras veces solo para moverlas de lugar. En este sentido un proyecto artístico contemporáneo, como Pandemonia Panacea, nos muestra multiplicidad de derivaciones por las capas de los cuerpos.

Pandemonia panacea: derivaciones subjetivas

Pandemonia es una figura, una obra de arte, un acontecer que quizás podamos inscribir dentro de la corriente del arte de acción ${ }^{2}$. Esta subjetividad fue creada y es puesta en acción en los grandes eventos de la moda mundial, pero hay ocasiones en que se comporta como un habitante más, y sale a recorrer los espacios de las grandes capitales del mundo: Londres, Madrid o Sao Paulo. Pandemonia va al supermercado, toma el té en una terraza cualquiera y con toda naturalidad anda por ahí buscando participar de la cotidianidad de las ciudades.

Su creador, un artista del Reino Unido, es completamente anónimo; su existencia pública -mediática, más bien-, acontece exclusivamente a través de su creación artística. El no existe, existe su creación; este ocultamiento es una manera de proteger que su obra no caiga en lo panfletario o el disfraz. En una entrevista a la televisión española, Pandemonia, plantea que ella es de alguna manera resultado y cuestionamiento a la actual cultura de la imagen, a la cultura del cuerpo que cada vez es más generalizada, a la obsesión por hacerse fotos de sí mismo en todo momento y lugar ${ }^{3}$.

En otra entrevista, reseñada en el Blog 9621, Pandemonia, aclara que ella no es una modelo, es más bien, una performista que se destaca entre el resto de las supermodelos por estar vestida siempre de látex, llamando la atención de personalidades y editorialistas. Ella piensa que su particular propuesta estética ilustra lo plástico que es el mundo de la belleza femenina, a la vez que encarna la idea de que la belleza no envejece ni cambia, ni se transforma.

1. El cuerpo sin órganos, es un concepto desarrollado por Gilles Deleuze y Félix Guattarri, en Mil Mesetas. Capitalismo y esquizofrenia. En este libro, la meseta número seis lleva por título: ¿Cómo hacerse a un cuerpo sin órganos? Por su parte, Juan Luis Pardo, titula El cuerpo sin órganos, a un estudio en el que se propone presentar la obra y el pensamiento de Deleuze.

2. El artista estadounidense Allan Kaprow, define el arte de acción como "un conjunto de acontecimientos llevados a cabo o percibidos en más de un tiempo y espacio... llevado a cabo de acuerdo con un plan, pero sin ensayo, público o repetición. Es arte, pero parece más cercano a la vida" (http://performancelogia.blogspot.com/2007/04/definicin-de-happeningallankaprow.html).

3. Entrevista a Pandemonia en RTVE La 2: Alaska y Coronas 03:20/14:01 (2014). 
Pandemonia, escenifica la manera como se configuran algunas subjetividades contemporáneas. Su performan constituye un modo de subjetivación que podemos nombrar como subjetividades celebrity. Esto es, una manera singular de configuración subjetiva, pero también podría tratarse de un semblante o mejor de un síntoma contemporáneo de nuestras propias maneras de acontecer en los contextos sociales actuales. ¡Tensiones! ¿Movimientos hegemónicos de dominación corporal? ¿Experiencia de subjetivación marginal? ¿Cuestionamiento a los cuerpos globalizados? ¿Prácticas de resistencia? ¿Subjetividades contestatarias?

Quizás Pandemonia, comprende todas estas cosas y a la vez ninguna, pues ella existe, en cuanto entra en relación con los otros; como experiencia o proyecto artístico está sujeta a las redes de lo impredecible. Ella sale, al igual que nosotros, al encuentro del acontecer del espectáculo de la vida, sin grandes teorías, se expone al acontecer cotidiano, exhibe su propia extravagancia, una que no pasa o mejor, que no acude a los circuitos gestuales de la racionalidad en busca del reconocimiento que homogeniza. La intensidad de lo extravagante, mueve a detenerse en estaciones imprevistas, a inventarse vidas, o quizás, solo a hilvanar el cuerpo con retazos de otras existencias.

Pandemonia, como todos nosotros, tiene días que exterioriza las costuras, y otros, en que vemos las fisuras que dejan costuras realizadas presurosamente, entonces, ella, como nosotros, deseamos que los demás, delicadamente giren el rostro, es esos momentos que entendemos que la oportunidad de ciertos giros es condición para la discreción. La extravagancia de ciertas obras de arte contemporáneo, también nos confrontan, pues nos piden cosas que no sabemos y en las que nosotros mismos nos desconocemos; quizás por ello, las identidades subjetivas y artísticas resultan cada vez más improbable, las identidades exigen fidelidad a lo pasado, a la memoria, aturdiendo la aventura de la creación.

Aventura y ausencia acentos de los modos de relación que propone Pandemonia, acentos que aluden a una manera de construirse -cuerpo látex-, y posibilitar acercamientos; su presencia, nos advierte de los permanentes deseos de conquista y dominación de los otros, pues la experiencia de coloniaje, también nos habita, a ella estamos demasiado cerca. Pandemonia, se presenta como una proximidad que acuna el acontecer de la experiencia humana, en sus movimientos por esa invención que denominamos espacio del transitar, por esos momentos intensos del darnos cuenta de sí.

La proximidad es la posibilidad de experimentar junto a los otros, las potencias del pensamiento, pues, el pensamiento constituye una experiencia y no una facultad o una operación mental. El pensamiento como experiencia sensible y corporal, se parece a las coreografías que dibujan los movimientos de los cuerpos en las estaciones, eso cuerpos que se entremezclan y se estremecen unos contra otros, unas veces con la ternura del cuidarnos, otras con el desenfreno por llegar a otros parajes. 
Las coreografías del pensar juntos, son ondas que vibran en todas las latitudes posibles, en todas las latitudes que necesitemos; experimentar juntos esas potencias coreográficas, para producir otras invenciones del cuerpo y de las subjetividades.

Pandemonia existe como subjetividad celebrity, desde unas decisiones personales: "vivo en una paradoja, soy un(a) desconocido(a) mientras mi trabajo artístico se va haciendo cada vez más famoso, es una experiencia muy peculiar" (Blog 9621), lo que responde igualmente a un conjunto de aspiraciones y búsquedas existenciales del estar en el mundo y participar con los demás de los aconteceres contemporáneos.

Nuestro mundo se encuentra poblado por subjetividades celebrity. Subjetividades que, al igual que Pandemonia, existen en el látex. El cuerpo-látex es la realización de un cuerpo puro, aséptico y traslúcido. Un cuerpo que se ha liberado de la incertidumbre de un cuerpo-carne, de un cuerpo supeditado a los dramas de lo orgánico. Las subjetividades celebrity, ostentan un protegido de las perplejidades del sexo y el erotismo, ¿cómo desea un cuerpo-látex? Pandemonia explica que ella encarna una forma femenina, no por la su singularidad de la feminidad, sino por cuanto ésta, es un vínculo útil para transmitir un mensaje ${ }^{4}$. La forma femenina para Pandemonia, viene a sustentar, vehiculiza un cuestionamiento político y configura una imagen totalizante, justo a esto pareciera estarse refiriendo Suely Rolnik (2002) cuando plantea que actualmente se pueden vislumbrar:

Verdaderas "identidades prêt-à-porter" de fácil asimilación, acompañadas de una poderosa operación de marketing que cabe a los medios fabricar y vehicular para hacer creer que identificarse con esas estúpidas imágenes y consumirlas es imprescindible para conseguir reconfigurar un territorio y, más aún, que este es el canal para pertenecer al disputadísimo territorio de una "subjetividad-lujo" (p. 3).

Subjetividades mercantiles, que parece ser portavoces de políticas públicas para combatir la epidemia de las arrugas e impulsar en la población la producción de pieles lustrosas y templadas como parches de tambor. Pandemonia ridiculiza las imposturas contemporáneas, las obsesiones por el lujo, la plasticidad de las relaciones y los intercambios.

Jean-Louis Déotte (2012), aludiendo a estas imposturas contemporáneas manifiesta que en los contratos de los actores en Hollywood "existe una cláusula de «clonación»; los actores aceptarán que sus clones actúen en las películas”..., y concluye su idea diciendo: "El porvenir es una cinematografía de la desaparición, ya que los fantasmas, indefinidamente repetidos y modificados, tomaran el lugar de los vivientes" (p.126). Hay un otro cyber-contemporáneo, carente de cuerpo y de órganos que deviene contratos y procedimientos, por algo la suplantación y el robo de identidades están a la orden del día; para protegerse, Pandemonia, elije su

4. Entrevista a Pandemonia en RTVE La 2: Alaska y Coronas 12:03/14:01 (2014). 
propia piel, explora materiales inciertos, dibuja los mapas para la proximidad como manera de estar y de aguardar; cambia de piel, cambiar de vestido, experiencia de dejar ir, dejarse ir para juguetear con lo que acontece en el estar próxima. Aprender del sauce que juguetea en lugar de llorar o mejor, que dispone su cuerpo al viento para acariciar, para arañar algo de la fugacidad del transcurrir.

\section{Alteridad radical: subjetividades-otro}

La manera de entender el fenómeno de la identificación en las sociedades contemporáneas, ha sufrido complejas transformaciones tanto en sus representaciones cotidianas, como en su articulación a la reflexión teórica. En los procesos de configuración de las subjetividades pareciera predominar una cierta identificación con una dimensión absoluta de los valores clásicos; no se aspira, por ejemplo, a un ideal de belleza, se aspira a la belleza en su pureza más absoluta.

Esto es lo que Pandemonia, exhibe en todo su esplendor, vive y es la realización plena del ideal de belleza, ella se presenta como una: "mujer sofisticada, delgada, muy alta, piel impecable, cabello brillante, look correcto y un cuerpo-látex", de manera que las subjetividades celebrity, ponen de relieve un cuerpo absoluto en el cual se produce la creación, y el arte contemporáneo superpone a esta experiencia corporal sus cuestionamientos a los modos de vida. Esta elección y repliegue sobre el cuerpo, quizás esté marcada por las dificultades de incidir en la construcción de un destino común, de manera que el cuerpo, se constituye en el soporte sobre el cual se decide y se produce la obra de arte.

Artistas destacadas como Orlan ${ }^{5}$ y Marina Abramović ${ }^{6}$, siguen este mismo trazado; obviamente, hacer del cuerpo el espacio subjetivo sobre, y con el cual expresarse, además de jugarse la propia existencia, no es una experiencia exclusiva del arte contemporáneo, esto mismo de otras maneras se presenta en todas las esferas de lo social. El cuerpo pues, deviene, campo de afirmación, cuerpo-voz, cuerpo-muro, cuerpo-forma, cuerpo-instrumento, cuerpo-escenario urbano y virtual. Existir en la contemporaneidad es entonces, la experiencia de darnos una forma, una forma fluida, como estaciones en temporadas. Así pues, las configuraciones subjetivas acontecen en el cuerpo y en el mundo, y éstas a su vez, le dan forma al cuerpo y al mundo.

Pandemonia como subjetividad celebrity, se da su propio cuerpo, uno que le permita fluir mejor por las tramas del lujo y la asepsia contemporánea. Pero el látex es solo un recubrimiento, el cuerpo-piel resiste en capas más internas, contiene

\footnotetext{
5. Ver página web https://www.orlan.eu/

6. Ver página web http://www.marinaabramovic.com/
} 
sus movimientos, sus impulsos arrebatados y su fuerza impetuosa. Este cuerpo contenido y persistente configura coros de voces, coreografías de aves migratorias que esculpen con palabras la fluidez de nuestro acontecer, del mismo modo que la luz del amanecer esculpe los rostros de las montañas.

Un cuerpo revestido de látex, es inmanencia en movimiento, suceder de unas formas en tensión a las fuerzas de esa cotidianidad que procura estacionar, homogenizar y domesticar. Pandeminia sabe que se recubre la superficie, para que afloren otras fuerzas, esas intensidades de los gestos que componen sonoridades que nos muevan a acariciar el mundo de manera distinta. Esto es, poner en acción una gestualidad experimental, un modo de conversar, de indagar e ir tras la aventura, como elefantes milenarios en sus viajes interminables.

También las mariposas monarcas conocen esta filosofía de lo gestual. Hay tanto que aprender de ellas, aprender la fortaleza de su conocimiento que es tan solo una cartografía para afrontar la existencia, guías de viaje a medio hacer. Conocimiento próximo, conocimiento atento a las pretensiones inocentes de formar a los demás. Las monarcas y los elefantes saben que el estar juntos, solo requiere de pequeños gestos de aproximación con los cuales trazar nuevos recorridos, en la cercanía de esos afectos que rozan sutilmente la corteza de los árboles, para evitar atemorizarlos.

En las sociedades contemporáneas, además del hacer, del pensar, del experimentar y del inventarse, las subjetividades precisan recrear-se en el propio cuerpo, parece ser la manera, como una subjetividad viene a decir quién es para sí y para los demás. Quizás por ello, las cirugías cosméticas, las dietas rigurosas, las sesiones interminables de entrenamiento corporal en los gimnasios, y el consumo de medicamentos, no son vistos como experiencias límites que ponen en riesgo la vida, al contrario, son condiciones de existencia, son parte de la oferta de subjetivación.

Alteridad radical, ${ }^{7}$ subjetividades-otro; conceptos que nombran la emergencia de subjetividades cuya pretensión de existencia está dada por la mirada de los demás, no importa de quien. Se acontece en un espacio-tiempo imaginado. Por ejemplo, en el número de seguidores en twitter, en facebook, en Instagram. El acontecer en un espacio-tiempo imaginado, permite situar ciertas rupturas con la tradición cultural de aquellos sujetos-cuerpos que se miraban en el espejo y éste les reconfortaba con una imagen de sí. Ahora pareciera estarse configurando subjetividades sin cuerpo, reflejos puros, imagen total; imágenes que circulan en el universo cibercultural. Jean Baudrillard (1991), se muestra bastante crítico frente a este movimiento subjetivo, por lo que se manifiesta con cierto desconcierto en relación a nuestro presente:

7. Concepto desarrollado por Jean Baudrillard, en el capítulo: El teorema de la parte maldita. En La transparencia del Mal $(115-120)$ 
También podremos cambiar a nuestro antojo el sexo al que pertenecemos, la pequeña parte del destino que nos queda, nuestro mínimo de fatalidad y de alteridad. Sin hablar de la cirugía estética de los espacios verdes, de la naturaleza, de los genes, de los acontecimientos y de la historia. (p. 21).

Programaspolíticosrecorrenelmundomediatizadosporaparatos yredestecnológicas, estos llevan incorporados sus propios proyectos estéticos hegemónicos, que buscan una estetización mercantil de la vida ${ }^{8}$ y dar consistencia a cuerpos-látex, científicos y tecnológicos. Ciencia ficción entreverada con ciencia cotidiana, configuran subjetividades donde la singularidad y el dramatismo de lo orgánico está ausente. ${ }^{9}$ Letizia cavernosa: vestida de autor, peinado estudiado, gestos ensayados, para representar su teatro del olvido, del olvido de sí. Los polluelos y jóvenes flamencos dudan a menudo del sentido de sus alas, pero al rato de haber emprendido el gran vuelo, perciben que también los planetas tienen alas para recorrer sus senderos cósmicos. Hay subjetividades que se presentan como pura ausencia y hasta el sol teme abrazar sus cuerpos. Sus rostros ausentes, es lo más parecido al infinito.

Pandemonia es al decir de su creador, una escultura capilar, y con ello se refiere a la producción de la subjetividad que pone en escena. Pandemonia es más que un vestido y sus accesorios, entre ellos una cartera y un perro, transparentes y vacíos. Su performance reconfigura el paisaje urbano, un paisaje subjetivo. Ella subvierte el circuito creación-contemplación, para entrar a proponer modos de relación. Modos de estetización abierta a los otros, como una-uno, más.

El performance de Pandemonia al igual que el de Letizia, en los medios televisivos, acontece como subjetividades-otro. Subjetividades de lo vacío, y, no precisamente por sus elecciones cognoscitivas o por la superficialidad que se les atribuye; su vacío es el espacio para contener el deseo de quien mira y no puede dejar de mirar, de mirarse. Su vacío es el espacio para que algo de nosotros mismos habite en ellas. Un deseo que alucina su propia caverna, mientras la existencia transcurre lánguidamente.

En estas prácticas contemporáneas de producción de subjetividades, donde el modelado corporal, las cirugías cosméticas, el tatuaje, las perforaciones (piercing), entre otras, emergen como síntoma, son el indicio de que algo de mayor amplitud y profundidad está aconteciendo. Prácticas en las que parece hacerse visible una multiplicidad de maneras de asumir la existencia, pero quizás se trate también, de unos modos contemporáneos de resistir a los embates de un sistema económico que pretende establecer relaciones univocas, y en espera de obediencia; por ello,

8. Expresión de Jacques Rancière en su libro Sobre políticas estéticas (pág. 14).

9. Paula Sibilia, pone de relieve la presencia de una bioprogramación contemporánea capaz de "formatear los cuerpos y las almas". 
se tornan tan importantes ciertas construcciones subjetivas que experimentan la expansión del pensamiento y sus formas sensibles.

Estas subjetividades y sus cuerpos inventados se despliegan en la improvisación, como la elocuencia de quien reinventa lo previsibles, para sentir la textura singular de las cosas y de los seres. Atreverse a atascar la voz, para explorar el vigor de los gestos, explorar sus lenguajes, dejar que los gestos también nos digan sus amaneceres.

Lo previsible es la estación de la repetición. Lo previsible suele retornar cada vez, de la misma manera que lo hace lo destructivo; lo previsible y lo destructivo parecen garabatear con las mismas herramientas y crear los mismos surcos en los cuerpos y en la vida. Previsibles y repetitivos son los delirios de poder en instituciones, así como lo son las tácticas estatales, las mismas que, a veces se presentan altamente refinadas, pero sus movimientos torpes, las delatan. Quizás las tácticas de las instituciones y de los estados, sean tan inventivas como la experiencia creadora. ¡Me aferro a creer que no sea de esa manera!

Una subjetividad suficientemente sutil, le puede dar consistencia a las nubes de arena, a la danza aérea de los estorninos, a la bruma y, a los atardeceres. Sutileza necesaria para conducirnos juntos por vías marginales. Tenue silencio, quietud ondulante, oscuridad traslucida, lugares donde los movimientos de la creación encuentren quietud, para inventarse otras potencias, otros cuerpos.

A modo de cierre

La circulación de Pandemonia Panacea por los escenarios más glamurosos nos plantea interrogantes en torno a la producción de las subjetividades contemporáneas, de sus maneras de acontecer, unas veces descifrables, otras incomprensibles en sus búsquedas y desvaríos. Las configuraciones subjetivas en la contemporaneidad representan diversas mudanzas, movimientos de los cuerpos para encontrar una forma, para darnos una forma con cierta consistencia y suficiente elasticidad; movimientos lentos para cuando necesitamos pensar despacio, a fuego lento, movimientos veloces para cuando necesitamos agitar el cuerpo y, oler las primeras lluvias, palpar el final de las sequias, aspirar las posibilidades de crear un pensamiento y producir otras experiencias.

Pandemonia Panacea, no es un recurso metafórico, es más bien, posibilidad de irrumpir en el mundo, pues la subjetividad es una experimentación compuesta por fluidos, unos días más densos que otros, cada fluido con su propio suceder. Las subjetividades contemporáneas están conformadas por fluidos de escasa densidad, y parecen acontecer cuando el tiempo, como continuidad cotidiana se queda suspendido para que germinen duraciones distintas. 
Una subjetividad celebrity se aproxima, con sus gestos se abre paso en la escena. Sus contorsiones turban, encienden otros florecimientos e insinúa vínculos imprevisibles. Pandemonia, a veces sigue guiones ensayados, nosotros también, pues no hay creación esencial, pero hay momentos en que las gramáticas aprendidas logran silenciarse, entonces los cuerpos dibujan, juguetean con los objetos y crean un paisaje posibles. Pandemonia susurra algo que no se alcanza a escuchar, momentáneamente la escena se petrifica, como quien sucumbe en el abismo de un abrazo intempestivo.

\section{Referencias bibliográficas}

Barthes, R. (2009). El susurro del lenguaje. Más allá de la palabra y la escritura. Barcelona: Paidós Ibérica, S. A.

Baudrillard, J. (1991). La Transparencia del Mal. Ensayo sobre los fenómenos extremos. Barcelona: Editorial Anagrama, S. A.

Bohm, D. (1988). La totalidad y el orden implicado. Barcelona: Editorial Kairós, S. A.

Deleuze, G. (2007). Empirismo y subjetividad. Barcelona: Gedisa.

Deleuze, G. y Guattari, F. (2012) ¿Cómo hacerse a un cuerpo sin órganos? En Mil mesetas. Capitalismo y esquizofrenia. Valencia: Pretextos.

Déotte, J. (2012). ¿Qué es un aparato estético? Benjamin, Lyotard, Rancière. Santiago de Chile: Ediciones Metales Pesados.

Kaprow, A. (s.f.). Perfermancelogia. Disponible en: http://performancelogia. blogspot.com/2007/04/definicin-de-happening-allankaprow.html Revisado: marzo $18 / 2014$

Pandemonia, Panacea. RTVE, L2. Alaska y Coronas. Disponible en: www.youtube. com/watch?v =TFdBfn8IyLo Revisado: febrero 19/2014

Pandemonia, Panacea. Blog 9621. Viste la calle. Disponible en: www.vistelacalle. com/ 58149/entrevista-a-pandemonia-panacea/. Revisado: marzo 15 /2014

Pardo, J. (2011). El cuerpo sin órganos. Presentación de Gilles Deleuze. Valencia: Pretextos.

Rancière, J. (2005). Sobre politicas estéticas. Barcelona: Museud'Art Contemporani de Barcelona. 
Rolnik, S. (2015, 26 febrero). El ocaso de la víctima: La creación se libra del rufián y se reencuentra con la resistencia. Recuperado de http:/www.unesco.org.uy/ci/ fileadmin/educacion /El\%20ocaso $\% 20 \mathrm{de} \% 201 \mathrm{a} \% 20 \mathrm{v} \% \mathrm{C} 3 \%$ ADctima $\% 20-\% 20$ NoFormal\%20JFIT.pdf).

Sibilia, P. (2005). El hombre postorgánico: Cuerpo, subjetividad y tecnologías digitales. Buenos Aires: Fondo de Cultura Económica (FCE). 